\title{
EXPLORING THE PREFERRED TEMPERATURE ON OCCUPANTS THERMAL COMFORT IN THE HUMID TROPICS
}

\author{
Harimi Djamila \\ School of Engineering \& Information Technology, Universiti Malaysia Sabah, KotaKinabalu Malaysia
}

\begin{abstract}
A field stud has been carried out in naturally ventilated residences in east Malaysia for the prediction and evaluation of the indoor comfort temperature using various methods and rigorous statistical analysis. The neutral temperature was predicted in our pre vious publication. The present paper aims to predict and examine the validity and reliability of the preferred temperature in naturally ventilated residential buildings. The preferred temperature was found to be lower than the neutral temperature by no less than $3^{0} \mathrm{C}$. The predicted indoor preferred temperature was assessed and compared with the results of other investigations carried out mostly in the humid tropics. We observed that the estimated preferred temperature was at the extreme lower of the recorded indoor temperatures; In fact this was seldom recorded. When validating the prediction, we observed that this situation also occurred in another large scale study carried out in the humid tropic of Indonesia. Therefore, the reliability of the prediction was addressed. Concluding remarks for future works investigations were suggested.
\end{abstract}

Keywords: Thermal Comfort, Preferred Temperature, Humid Tropics, Field Study

\section{INTRODUCTION}

The outdoor climate has always been considered as the main issue in building thermal design for the occupants' indoor thermal satisfaction. Indoor climate can either be controlled artificially by air conditioning or by passive means. Most developed countries opted for active heating and/or cooling using air-conditioning because of massive energy supply in the 1950s. Consequently, an international building style was born having no geographic or climatic zone boundaries. The designer becomes more concerned with the aesthetic building outlook. The uncomfortable indoor thermal environment turned into a mechanical issue to be solved solely by the installation of air-conditionings. However, concerns have been raised that the energy consumption and primarily the burning of fossil fuels is the major driving factor in global warming. As a result, several cities in the world are getting hotter and hotter such as Shanghai, Tokyo, Los Angles, Oakland, Kuala Lumpur, and many others [1]. The amount of energy required for airconditioned spaces depends closely on the desired indoor air temperature.

A difference of temperature by $10 \mathrm{C}$ between indoors and outdoors adds $10 \%$ to greenhouses gas emissions such as carbon dioxide [2]. The results of a field survey in Indonesia showed that the residences with air-conditioning consume nearly twice the amount of energy compared to houses without air-conditioning [3].

The situation is different for those living in naturally ventilated building as active cooling is not the primary tool in achieving thermal comfort with the surrounding indoor environment and occupant can adjust to the indoor climate accordingly. Passive building design with thermal comfort approach under such situation is mostly concerned with building materials and building design for occupant thermal satisfaction. However, this requires knowledge of the indoor climate, occupants' thermal comfort, occupant tolerance to the indoor temperature, occupant thermal preference toward the indoor thermal condition, occupant thermal behavior under various indoor climatic conditions. This is critical because, it has been already observed that what is perceived as thermally comfortable by the building occupant as opposed what is practiced by engineers is different [4].

National and international Standards are usually considered the best references for the indoor thermal comfort predictions. International Standards are the results of extensive thermal comfort researches but with their own shortcomings and limited scopes.

The concept and definition of thermal comfort dictates the desired indoor thermal environment which may not reflect the occupant concept specifically in residential buildings. The comfort temperature seems to be more connoted to the preferred temperature than the neutral temperature. However, this may have implications in terms of energy consumption.

This is because even when occupant feels thermally neutral may still prefers either to be cooler under warmer climate or warmer under cooler climate as observed in many investigations [5,6]. Preferred temperature can be defined as the indoor temperature which most likely produces 'no change' 
on the McIntyre thermal preference scale [7]. This study is concerned in exploring and discussing the preferred temperature based on McIntyre scale in the humid tropics of Malaysia. The McIntyre preference scale is a known scale which has been widely used for the determination of the indoor preferred temperature.

\section{METHODOLOGY}

The field study took place in Kota Kinabalu city located on the coastline of Sabah state at 5056' N Latitude, 116003' Longitude in a tropical hot-humid environment (East Malaysia). The survey was carried out in forty two buildings locations. The research was carried out in residential buildings only. The number of the surveyed subjects was 949 records. Records were reduced to 890 when filtered against the criteria established before analysis. The research design and method are well described in our previous publication [15] and therefore we will not repeat it here; similarly for instrumentation and measurement protocol.

The preferred temperature is referred to the perceived temperature based on McIntyre scale (Cooler, No Change, and Warmer). Descriptive statistics of all the measured variables is well explained in the stated above reference. So, the reader may refer to it for farther details for the collected indoor thermal environmental parameters.

\section{RESULTS AND DISCUSSION}

Relative frequencies of votes on McIntyre scale are plotted at various indoor air temperatures in Figure 1.

The McIntyre scale has three categories; want to be 'cooler' ($1)$, 'no change' $(0)$, want to be 'warmer' $(+1)$. The mean average vote on McIntyre scale was about $-0.55 \pm 0.03$.

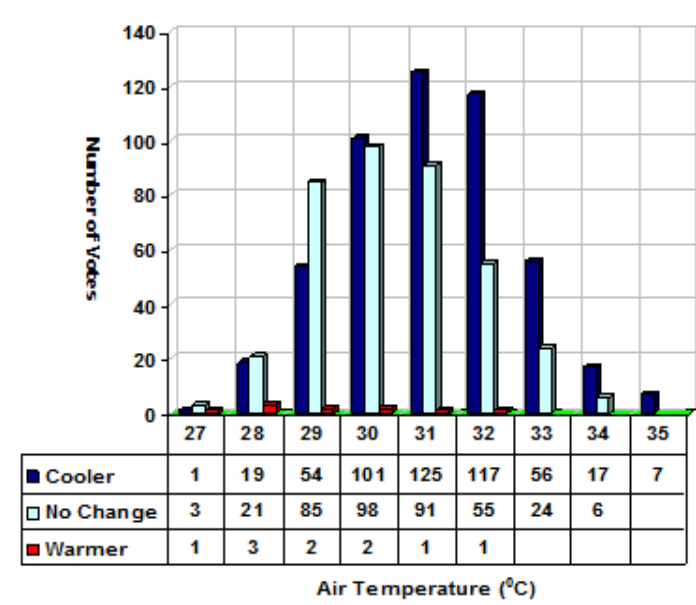

Fig 1 Air temperature vote distribution on McIntyre scale $\left(1^{0} \mathrm{C}\right.$ Bin)
The number of occupants wanted to be 'cooler' exceeded considerably these who wanted to be 'warmer'; nearly $58 \%$ of the occupants voted for ' "cooler', while $43 \%$ and $1 \%$ preferred 'no change' and 'warmer' respectively. For the indoor air temperature below neutrality, more than $56 \%$ of them voted for 'no change', and at least 39\% and 3\% preferred 'cooler' and 'warmer' in that order. At the indoor neutral temperature of $30^{\circ} \mathrm{C}$, the percentage of occupants who wanted to be 'cooler' was roughly equal to those who preferred 'no change'. When the indoor temperature was above neutrality, occupants' preference toward 'cooler' surpassed those who wanted 'no change'. It has been suggested that perhaps people in warm climates prefers to feel cooler than neutral, while people in cold climates might prefer to feel warmer than neutral [6].

The obtained results of temperature preference were consistent with the works of several researchers $[9,10,11]$ and many others. This phenomenon, as explained by Feriadi and Wong [10) in their field study was due to that the neutral indoor temperature at the moment of survey may not reflect the indoor condition that people would prefer to be. In their investigation, Feriadi and Wong [10] found $74 \%$ of the votes were for want to be 'cooler' which was considered according to the authors as extreme. Busch [11] in a field study conducted in Thailand observed that $64 \%$ of the occupants in naturally ventilated offices wanted to feel cooler even while experiencing neutral thermal sensation. In this investigation, nearly $46 \%$ of the occupants wanted to be 'cooler' while voting 'neutral'.

It was also observed that $43 \%$ of the occupants voted for 'no change'. Of the subjects feeling 'slightly cool', practically $56 \%$ of them voted for 'no change'. Yet when they were feeling 'slightly warm' only $26 \%$ preferred 'no change' and $74 \%$ wanted to feel 'cooler'. Overall only handful of the occupants desired to be 'warmer'. It must be highlighted that some questionnaires were removed from the present analysis either during the time of the survey or prior analysis. For instance, if the subject voted for all the questions at the extreme scale or provided obvious inconsistent answers, the questionnaire was automatically removed from this analysis. Adding to that, the temperature in Malaysia is hot all year round, and therefore preferring cooler environment seems to be obvious choice.

Figure 2 is used for more detailed evaluation of the relationship between the mean preference votes and mean indoor air temperatures. The regression line has the equation:

$$
\begin{gathered}
\left(\mathrm{r}^{2}=0.927 ; \text { Adjusted } \mathrm{r}^{2}=0.903, \mathrm{~F}=38.12, P \text { value }=.000\right) . \\
T_{p_{(\text {mean })}}=0.0054 T_{a(\text { mean })}{ }^{2}-0.4355 T_{a(\text { mean })}+7.763:
\end{gathered}
$$

Where, $T_{p_{(\text {mean })}}$ is the mean votes on McIntyre thermal preference scale. The first term of the equation is close to zero and a linear regression might be acceptable. However when residuals were plotted against fitted values, a curvature of the 
relationship between the two variables was apparent and therefore quadratic regression was kept.

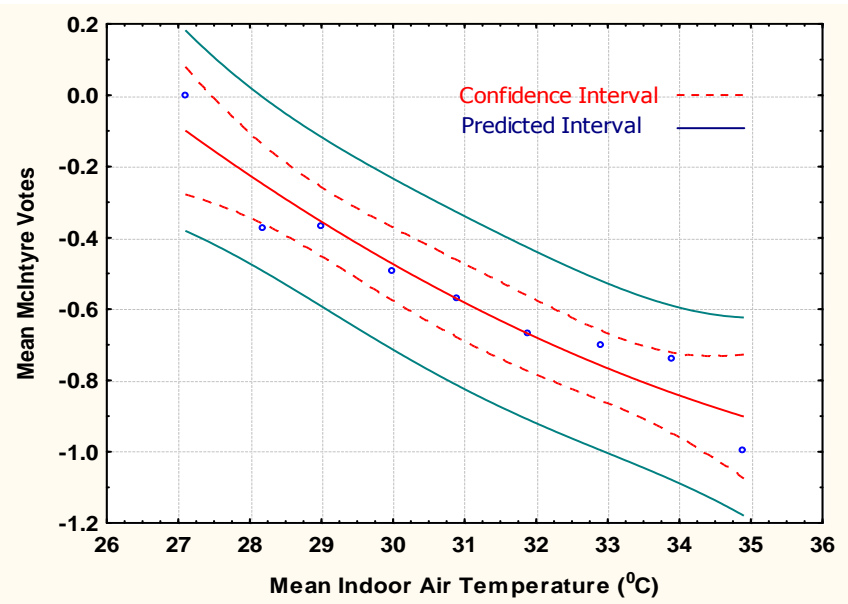

Fig 2 Mean McIntyre thermal preference votes per temperature bin vs. mean indoor temperature in the bin

Figure 2 shows that the regression line did not cross the $\mathrm{x}$-axis within the indoor temperature range under investigation and also shown the confidence interval and the wide range of the predicted interval. When solving the above equation, the preferred temperature yielded to $26.6{ }^{\circ} \mathrm{C}$. The determined preferred temperature might probably be reviewed as an extrapolation outside the range under investigation when considering the mean indoor temperature $\left(1^{0} \mathrm{C}\right.$ bin $)$ though it is very close to the lowest value. It can be stated that the optimum preferred temperature would not be ensured without active cooling most of the time. A question that may raise is that what would be the result if the McIntyre scale have identical sevenpoint scale as the ASHRAE scale but holds the McIntyre concept which is 'would you like to be'. This question has been raised and answered earlier by Hymphreys et a.l [16] in the UK and replication of such investigation in the humid tropics is worth pursuing for better understanding of the implication of the preferred temperature on energy consumptions.

Several researchers used probit analysis to determine the preferred indoor temperature. The preferred indoor temperature as outlined or applied in several studies $[12,13$, and 8$]$ is the temperature at the intersection of two regressive curves from 'want to be warmer' and 'want to be cooler' analysis. The preferred temperature in the McIntyre scale is then determined by equating the two probit models.

In the present investigation, Logit regression was selected as both methods provide similar results. The reader may refer to statistical books for further insight. The frequency analysis of votes were first grouped at $1^{\circ} \mathrm{C}$ intervals in ascending order, treating all values as lying at the center of the interval and then the mean of the interval was estimated for higher possible accuracy. These are presented in Table 1 with their corresponding standard deviation values. For occupants who wanted to be warmer, the following Logit regression was determined.

$$
\operatorname{Logit}\left(p_{\text {oww }}\right)=+22.17-0.89 T_{a}
$$

For these who wanted to be cooler, the following regression was found

$\operatorname{Logit}\left(p_{\text {owc }}\right)=-10.129+0.338 T_{a}$

Table 1 Frequency distribution of thermal preference votes per $1^{0} \mathrm{C}$ of the mean bin indoor air temperature

\begin{tabular}{|c|c|c|c|c|c|c|}
\hline \multirow{2}{*}{$\begin{array}{c}\text { Mean } \\
\text { Ta } \\
\left({ }^{0} \mathbf{C}\right)\end{array}$} & \multirow{2}{*}{ Range } & \multirow{2}{*}{ SD } & \multicolumn{3}{|c|}{ McIntyre Scale } & \multirow[b]{2}{*}{ Total } \\
\hline & & & -1 & $\mathbf{0}$ & 1 & \\
\hline 27.1 & 26.5 to $<27.5$ & 0.38 & 1 & 3 & 1 & 5 \\
\hline 28.2 & 27.5 to $<28.5$ & 0.19 & 19 & 21 & 3 & 43 \\
\hline 29.0 & 28.5 to $<29.5$ & 0.28 & 54 & 85 & 2 & 141 \\
\hline 30.0 & 29.5 to $<30.5$ & 0.29 & 101 & 98 & 2 & 201 \\
\hline 30.9 & 30.5 to $<31.5$ & 0.29 & 125 & 91 & 1 & 217 \\
\hline 31.9 & 31.5 to $<32.5$ & 0.28 & 117 & 55 & 1 & 173 \\
\hline 32.9 & 32.5 to $<33.5$ & 0.28 & 56 & 24 & 0 & 80 \\
\hline 33.9 & 33.5 to $<34.5$ & 0.34 & 17 & 6 & 0 & 23 \\
\hline 34.9 & 34.5 to 35.3 & 0.31 & 7 & 0 & 0 & 7 \\
\hline \multicolumn{3}{|c|}{ Total } & 497 & 383 & 10 & 890 \\
\hline
\end{tabular}

SD: Standard Deviation

Table 2 presents the observed and computed values of occurrence of the two cases 'want to be warmer' and 'want to be cooler'. The expected results are quite close to the observed values having less than $10 \%$ of residuals (Observed Predicted) except at the indoor air temperature of $34.9{ }^{\circ} \mathrm{C}$ for the case 'want to be cooler' as illustrated in Figure 3.

Table 2 Observed and computed frequency of votes

\begin{tabular}{|c|c|c|c|c|c|}
\hline \multirow{2}{*}{$\begin{array}{c}\text { Ta } \\
\left({ }^{0} \mathrm{C}\right)\end{array}$} & \multicolumn{2}{|c|}{ Want to be Warmer } & \multicolumn{2}{c|}{ Want to be Cooler } & \multirow{2}{*}{ Total } \\
\cline { 2 - 5 } & Expected & Observed & Expected & Observed & \\
\hline 27.1 & 0.619 & 1 & 1.37 & 1 & 5 \\
\hline 28.2 & 2.26 & 3 & 15.05 & 19 & 43 \\
\hline 29 & 3.51 & 2 & 59.14 & 54 & 141 \\
\hline 30 & 2.17 & 2 & 100.45 & 101 & 201 \\
\hline 30.9 & 1.03 & 1 & 125.34 & 125 & 217 \\
\hline 31.9 & 0.34 & 1 & 113.42 & 117 & 173 \\
\hline 32.9 & 0.06 & 0 & 58.25 & 56 & 80 \\
\hline 33.9 & 0.01 & 0 & 18.096 & 17 & 23 \\
\hline 34.9 & 0 & 0 & 5.885 & 7 & 7 \\
\hline
\end{tabular}


Overall the regressions provided a good fit with the claimed frequency distribution, the $95 \%$ fiducial band was very large for the case of 'want to be warmer'. It must be emphasized that most of thermal comfort field studies do not consider the confidence limits in the prediction of the preferred temperature, though the predicted preferred temperature could be affected by the precision of the model.

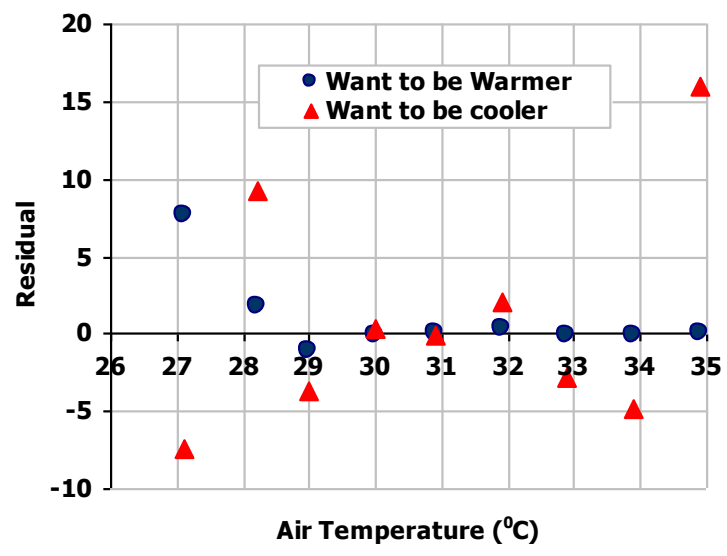

Fig 3 Residuals of predicted percentage of frequency in McIntyre scale

At the preferred temperature, $\left(p_{o w w}=p_{o w c}\right)$. Therefore, $\left(T_{P}=26.3^{0} \mathrm{C}\right)$ is the preferred indoor temperature as depicted in Figure 4. The obtained result was close to that found when using quadratic regression. At the preferred temperature, more than $20 \%$ of the occupants may want to be either 'cooler' or 'warmer' and the majority may prefer 'no change'.

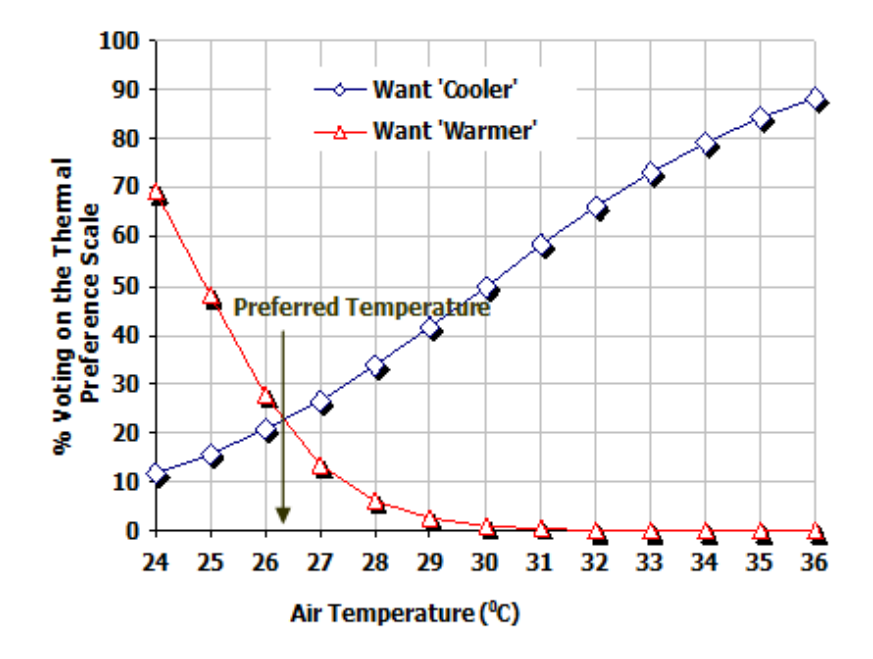

Fig 4 Logit regression model fitted to thermal preference votes

The obtained preferred temperature was $3.7^{0} \mathrm{C}$ lower than the indoor neutral temperature. This temperature is closer to the lowest temperature recorded in the conducted survey. Brager et $a l$. [14] stated that the central category of the McIntyre scale is very strict in defining thermal satisfaction. Whereas, Humphreys et al. [6] reported that McIntyre scale discloses a lifestyle desire rather than a comfort state. This is because in hot climate people have a tendency to prefer lower temperatures than the neutral temperature and the reverse is also true when people subjected to cold environment. Conversely to the previous opinions, Newsham and Tiller [7] mentioned that thermal preference scale is more relevant than the ASHRAE thermal sensation scale as people according to the same author adjust their thermostats based on a similar question of 'Would I prefer to be warmer, cooler, or the same'. However, this may not be the case for naturally ventilated building. This is because occupants have some financial restrictions and thereby have limited control over their indoor environments.

Wong and Khoo [8] in their field study in classrooms in Singapore also found that the preferred temperature was lower than the indoor neutral temperature by $3.5^{\circ} \mathrm{C}$. Feriadi and Wong [10] found that $26.03^{\circ} \mathrm{C}$ was the preferred indoor operative temperature for naturally ventilated houses in Indonesia which was $3.1^{\circ} \mathrm{C}$ lower than the indoor neutral operative temperature. We observed from their published study that the preferred temperature also was rarely recorded during their field survey.

Humphreys and Hancock (2007) used a survey to explore the variation of the desired thermal sensation on the ASHRAE scale and how it may affect the conclusions which might be drawn from a comfort survey. They asked their subjects to indicate their thermal preference based on the ASHRAE scale. According to the author, this method has the advantage of recording immediate information about the desired sensation, whereas the McIntyre scale provides the desired sensation when a respondent desires 'no change'. Additionally, the present study showed some statistical issues when using McIntyre Scale for the assessment of subjects' thermal preference in the humid tropics. Further investigation in using ASHRAE for the assessment of subjects' thermal preference in the humid tropics will definitively provide better insight.

\section{CONCLUSIONS}

The preferred indoor air temperature from logit regression was found to be lower by $3.7^{\circ} \mathrm{C}$ than the indoor neutral temperature. It is about $26.3^{0} \mathrm{C}$. Detailed regression analysis revealed the limitation of the prediction when considering the fiducial band. The reliability of the prediction of the preferred temperature when using McIntyre scale is not clear yet. This is due to the narrow range of the indoor air temperatures in the humid tropics, and also due to the hot indoor temperature reflected by the recorded mean indoor air temperature. It is apparent that the preferred temperature may not be achieved with passive means specifically in the humid tropics. Alternatively, the use the 
ASHRAE scale for the prediction of the preferred air temperature in naturally and mechanically ventilated buildings will certainly provide insight about thermal comfort in the humid tropics

\section{REEFERENCES}

[1] Davis M.P., Ghazali M., Nordin N.A., Thermal Comfort Honeycomb Housing. Dar Ehsan, Selangor, Malaysia,: 2006.

[2] G.H.O. (Green House Office). A Home Guide to Reducing Energy Costs and Greenhouse Gases, Australia,

http://www.greenhouse.gov.au/gwci/pubs/coolit.pdf. Retrieved 20 September 2006.

[3] Tomoko U., Shuichi H., Sri Nastiti N. E., Ekasiwi, Reduction in Energy Consumption by Air-Conditioner in Residences under Hot and Humid Climates. The 2005 World Sustainable Building Conference SB05, September 27-29, 2005, Tokyo, Japan .

[4] Darby S. and White R., Thermal Comfort Oxford: Environmental Change Institute, University of Oxford, 2005.

[5] de Dear R., Brager G., Cooper D., Developing an adaptive model of thermal comfort and preference, Final Report ASHRAE RP-884. Sydney, Australia: Macquarie Research Ltd., Macquarie University, and California, USA: Center for Environmental Design Research, University of California, 1997.

[6] Humphreys M. A., Nicol J F., Raja I A, Field studies of indoor thermal comfort and the progress of the adaptive approach, Advances in Building Energy Research, Vol. 1, pp. 55-88, 2007.

[7] Newsham G.R. and Tiller D.K., A Field study of office thermal comfort using questionnaire software, IRC Internal Report 708, Institute for Research in Construction, Canada, 1995.

[8] Wong N.H. and Khoo S.S., Thermal comfort in classrooms in the tropics, Energy and Buildings, Vol. 35, pp. 337-351, 2003.

[9] McIntyre D.A., Chamber studies - Reductio ad absurdum, Energy and Buildings, Vol.5, pp. 89-96, 1982.

[10] Feriadi H. and Wong N.H., Thermal comfort for naturally ventilated houses in Indonesia, Energy and Buildings, Vol.36, pp. 614-626, 2004.

[11] Busch J.F., A tale of two populations: Thermal comfort in air conditioned and naturally ventilated offices in Thailand, Energy and Buildings, Vol.18, pp. 235-249, 1992.

[12] de Dear R., Fountain M., Field experiments on occupant comfort and office thermal environments in a hot-humid climate, ASHRAE Transactions, Vol. 100, pp., 457-75, 1994.
[13] Hwang R.L., Lin T.P., Kuo N.J. , Field experiments on thermal comfort in campus classrooms in Taiwan. Energy and Buildings, Vol. 38, pp. 53-62, 2006.

[14] Brager G.S., Fountain M.E, Benton C.C., Arens A.E., Bauman F.S, A Comparison of Methods for assessing thermal sensation and acceptability in the field, Proceedings of Thermal Comfort: Past, Present and Future. BRE, London. 17-38, 1994.

[15] Harimi Djamila, Chu Chi Ming, Sivakumar Kumaresan, Field study for prediction and evaluation of thermal comfort in residential buildings in the equatorial hothumid climate of Malaysia, Building and Environment, Vol. 62 , pp. 133-142, 2013.

[16] Humphreys M.A. and Hancock M, Do people like to feel "Neutral"? Exploring the variation of the desired thermal sensation on the ASHRAE scale, Energy and Building, Vol. 39, pp. 867-874.

\section{BIOGRAPHIE}

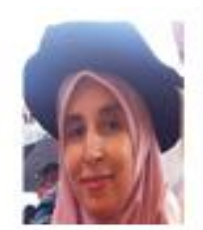

Dr. Harimi Djamila is a senior lecturer at Universiti Malaysia Sabah. She is an active researcher (Thermal and Environmental Research Group). Her area of research includes Thermal Comfort, Building Thermal Simulation, and Housing Passive Design. She is interested in worldwide research collaboration

E-mails:

harimi1@yahoo.fr

djamila@ums.edu.my 